\title{
Clinicopathologic and immunohistochemical features of gastrointestinal stromal tumors: a single-center experience
}

Ozlem Zeliha Sert, Hilmi Bozkurt, Tolga Olmez, Emre Aray, Selcuk Gülmez, Aziz Serkan Senger, Erdal Polat, Mustafa Duman

Department of Gastrointestinal Surgery, Kosuyolu Education and Research Hospital, Istanbul, Turkey

Submitted: 27 November 2019

Accepted: 9 February 2020

Arch Med Sci Civil Dis 2020; 5: e8-e13

DOI: https://doi.org/10.5114/amscd.2020.93475

Copyright @ 2020 Termedia \& Banach

\section{Abstract}

Introduction: Here we present our 10-year experience regarding gastrointestinal stromal tumors (GISTs) in terms of clinicopathologic features and immunohistochemical staining patterns.

Material and methods: In this single-center retrospective study, during 2008-2018, data of 26 patients with histologically confirmed diagnoses of GISTs were collected. All patients included in the study underwent surgical resection. The Mann-Whitney $U$ test was used for continuous variables.

Results: The mean age of the patients was $60.7 \pm 10.4(35-79)$ years. The most common GIST location was the stomach (88.5\%). The mean tumor size was $5.8 \mathrm{~cm}(1-13 \mathrm{~cm})$ and the most common histologic type of GIST was spindle cell (61.5\%). CD 117 (c-kit) was positive in $96 \%$ of GIST cases, while CD34 was positive in $84.6 \%$, discovered on GIST-1(DOG1) in $46.2 \%$, smooth muscle actin (SMA) in $26.9 \%$, S100 in $19.2 \%$, and desmin in $7.7 \%$. In one CD117 negative patient, DOG 1 was positive. Four patients had metastases (15.4\%). The mean follow-up time was $56.5 \pm 36.2$ month. The length of hospital stay was significantly longer in patients who had small intestinal GIST $(p=0.010)$. In immunohistochemical staining, SMA was significantly more common among spindle cell type $(p=0.032)$.

Conclusions: GISTs are very rare tumors of the gastrointestinal tract, but the accurate diagnosis with immunohistochemical staining is vital for the treatment. So, large scale, prospective and randomized multicenter trials are needed to reduce the misdiagnosis rate of GISTs.

Key words: immunohistochemical staining, gastrointestinal stromal tumors, metastases.

\section{Introduction}

Gastrointestinal stromal tumor (GIST) is the most common mesenchymal tumor in the digestive tract [1]. They are considered to originate from the interstitial cells of Cajal, but the exact cell(s) of origin for GISTs is unknown $[2,3]$. Most GISTs, nearly $85-90 \%$, have c-KIT (CD117) or platelet-derived growth factor receptor $\alpha$ (PDGFRA) mutations. KIT and PDGFRA are tyrosine kinase receptors for stem cell factor and platelet-derived growth factor $\alpha$ respectively. The KIT-negative GISTs are usually positive for DOG1, a calcium activated chloride channel protein also expressed in Cajal cells [4].

\author{
Corresponding author: \\ Ozlem Zeliha Sert \\ Department of \\ Gastrointestinal Surgery \\ Kosuyolu Education \\ and Research Hospital \\ Istanbul, Turkey \\ E-mail: drzozlemsert@gmail. \\ com
}


The most common organ sites are stomach (50-60\%), small intestine (20-30\%), colon and rectum (10\%) [5]. The liver and the peritoneal cavity are the primary sites of metastasis [6]. GISTs have up to $30 \%$ of malignancy potential. They are classified as "very low, low, intermediate or high" to determine the risk of their malignancy [7]. Miettinen demonstrated that the metastatic risk of GISTs increases with the tumor size regardless of the mitotic count [8]. Complete surgical resection with protecting the capsule is the mainstay treatment of GISTs [9].

Histologic features of GISTs are spindled, epithelioid or mixed (spindled and epithelioid) type. The most common histologic type is spindle cell [10]. The histopathologic features of GISTs in resection material are crucial in postoperative management, treatment and determining prognosis of the patients.

This paper provides an overview of the clinicopathologic and immunohistochemical features of GISTs.

\section{Material and methods}

All patients diagnosed with GIST in a gastrointestinal surgery clinic, between 2008 and 2018, were retrospectively evaluated. The study protocol was approved by the Ethics Committee of Teaching and Research Hospital (number 2019.4/13 190) and the study was conducted in accordance with the principles of the Declaration of Helsinki (revised in 2013). Demographic data such as age, gender and body mass index (BMI) were recorded. Operating time, length of hospital stay, follow-up time and survival rate were also collected. On the other hand, size and the type of the tumor, metastases rate, predominant cell type, Ki67 proliferation index, number of mitoses/50 high power fields (HPF), the presence of necrosis and hemorrhage were also evaluated.

The risk stratification of patients was evaluated according to the Armed Forces Institute of Pathology (AFIP) classification (Miettinen and Lasota criteria). Accordingly, tumors were classified as very low-risk, low-risk, intermediate risk or highrisk, based on tumor localization (stomach, ileum, rectum), mitotic rate ( $\leq 5 / 50 \mathrm{HPF}$ or $>5 / 50 \mathrm{HPF})$ and tumor size $(\leq 2 \mathrm{~cm},>2-\leq 5 \mathrm{~cm},>5-\leq 10 \mathrm{~cm}$ and $>10 \mathrm{~cm})[11]$.

Immunohistochemical reactivity to the following antibodies was noted: CD117, CD34, SMA, S-100, Desmin, and DOG1. Unfortunately, we could not investigate PDGFRA mutation. The criteria for the diagnosis of GIST was based on hematoxylin and eosin (H\&E) analysis and an immunohistochemistry panel including CD117, CD34, DOG1, SMA, S-100 protein, desmin and Ki67, and was standardized by the pathology department.

\section{Statistical analysis}

To summarize the data obtained from the study the results were presented as mean \pm standard deviation or median and range. Categorical variables were summarized as number and percentage. Normality checks of the numerical data were performed by the Kolmogorov-Smirnov test. Fisher's exact was used to compare categorical variables. The Mann-Whitney $U$ test was used when the continuous variables were not normally distributed. Jamovi and JASP software were used for the statistical analyses and $p<0.05$ was accepted as statistically significant.

\section{Results}

The patient group included 19 (73.1\%) male and 7 (26.9\%) female patients. The male-to-female ratio was approximately $3: 1$. Age of the patients ranged from 35 to 79 years, mean age of $60.7 \pm 10.4$ years. The mean BMI of the patients was $28.5 \pm 3.5 \mathrm{~kg} / \mathrm{m}^{2}\left(22-36 \mathrm{~kg} / \mathrm{m}^{2}\right)$. The mean operation time was $168.8 \mathrm{~min}(60-500 \mathrm{~min})$. Of the 25 patients who underwent curative resection, one patient had severe peritoneal carcinomatosis, so debulking surgery was performed.

The most common GIST location was the stomach $(88.5 \%)$, followed by the small intestine. The mean tumor size was $5.8 \mathrm{~cm}(1-13 \mathrm{~cm})$. Moreover, the most common histologic type of GIST was spindle type (61.5\%). Table I shows the demographic and pathological characteristics of the patients.

According to the AFIP classification, the majority of the patients were in the low risk category (34.6\%). 8 (30.8\%) patients were in the high risk, $5(19.2 \%)$ in the very low risk and $4(15.4 \%)$ in the intermediate risk category. The majority of the cases showed mitotic activity of equal to or less than < 5/50 HPF as a whole (mean 3.0). In addition, the mean Ki 67 proliferation index was 3.0.

CD 117 (c-kit) was positive in $96.2 \%$ of GIST cases, while CD34 was positive in $84.6 \%$, DOG1 in $46.2 \%$, smooth muscle actin (SMA) in $26.9 \%$, S100 in $19.2 \%$, and desmin in $7.7 \%$. In two CD117 negative patients, DOG1 was positive. Four (15.4\%) patients had metastases. The mean follow-up duration was $56.5 \pm 36.2$ months.

There was no difference in terms of demographic and pathologic features between the gastric and the small intestinal GISTs. Only the length of hospital stay was significantly longer in patients who had small intestinal GIST $(p=0.010)$ (Table II).

The rates of metastasis and survival were comparable in both groups. In general, the two groups did not show a significant difference regarding immunohistochemical staining and expression 
Table I. Demographic and pathological characteristics of patients with gastrointestinal stromal tumors

\begin{tabular}{|c|c|}
\hline Parameter & Results \\
\hline \multicolumn{2}{|l|}{ Gender: } \\
\hline Male & $19(73.1)$ \\
\hline Female & $7(26.9)$ \\
\hline Age & $\begin{array}{c}60.7 \pm 10.4 \\
60.0(35.0-79.0)\end{array}$ \\
\hline BMI & $\begin{array}{c}28.5 \pm 3.5 \\
30.0(22.0-36.0)\end{array}$ \\
\hline \multicolumn{2}{|l|}{ Tumor site (\%): } \\
\hline Stomach & $23(88.5)$ \\
\hline Small intestine & $3(11.5)$ \\
\hline Operation time [min] & $168.8(85.8)$ \\
\hline Tumor size & $5.8(3.2)$ \\
\hline \multicolumn{2}{|l|}{ Histologic type: } \\
\hline Spindle & $16(61.5)$ \\
\hline Mixed & $8(30.8)$ \\
\hline Epithelioid & $2(7.7)$ \\
\hline SMA & 7 (26.9) \\
\hline DOG1 & $12(46.2)$ \\
\hline S100 & $5(19.2)$ \\
\hline Desmin & $2(7.7)$ \\
\hline Ki67 & $3.0(1.0-30.0)$ \\
\hline $\mathrm{Cd} 34$ & $22(84.6)$ \\
\hline Cd117 & $25(96.2)$ \\
\hline Mitotic activity/50HPF & $3.0(1.0-47.0)$ \\
\hline \multicolumn{2}{|l|}{ Risk: } \\
\hline Very low risk & $5(19.2)$ \\
\hline Low risk & $9(34.6)$ \\
\hline Intermediate risk & $4(15.4)$ \\
\hline High risk & $8(30.8)$ \\
\hline Necrosis & $9(34.6)$ \\
\hline Hemorrhage & $17(65.4)$ \\
\hline Metastasis & $4(15.4)$ \\
\hline Complication & $5(19.2)$ \\
\hline Length of hospital stay & $7.0(4.0-15.0)$ \\
\hline \multicolumn{2}{|l|}{ Survival: } \\
\hline Alive & $23(88.5)$ \\
\hline Mortality & $3(11.5)$ \\
\hline Follow-up [months] & $56.5 \pm 36.2$ \\
\hline
\end{tabular}

Descriptive statistics are given as mean $\pm S D$ and number (\%). patterns except that staining with SMA was significantly more common among spindle cells $(p=0.032)$ (Table III).

\section{Discussion}

GISTs are known as mesenchymal tumors which are reported to be rare because they are generally misdiagnosed.

In this study, in 26 patients treated at the Gastrointestinal Surgery clinic based on positive expression of CD117 antigen, diagnosis of GIST was confirmed in $25(96.2 \%)$ patients. As it showed, the result of KIT expression was not sensitive enough for all patients. A recent study on the GIST genetic cross section illustrates that mutation of the proto-oncogene $\mathrm{c}-\mathrm{KIT}$, besides mutation in the tyrosine kinase KIT gene, is also displayed by changes in PDGFRA [12].

Diagnosis of GIST should be based on immunohistochemically positive CD117 or DOG1, as required by standards [13, 14]. Recent studies have shown that CD117 and DOG1 positivity rates are similar (84-95\%) [15]. In this study, DOG1 was positively expressed in the one CD117 negative case. On the other hand, Kiśluk et al. found a significant difference between DOG1 tumor histological types [16].

In our study, similarly with the literature, the most common location of the GIST was the stomach [17]. GISTs are usually seen in older adults of age greater than 50 years [18]. In this study, the mean age was 60 years. Tumor diameter and mitotic rate are reliable markers accepted by many authors to determine prognosis [19-22]. In the present study, the mean tumor size was $5.8 \mathrm{~cm}$. Miettinen et al. reported that tumors larger than $10 \mathrm{~cm}$ had increased risk of metastases [8]. For another prognostic factor, Ki67 proliferation index, except for small bowel GISTs, a value more than $10 \%$ has been shown to be associated with poor prognosis [23, 24]. Our cases were localized predominantly in the stomach and also had a low proliferation index.

Spindle cell type is the most common histologic type in the literature $[25,26]$. As in the literature, the most common histologic type of GIST was spindle cell type (16 cases, $61.5 \%$ ), followed by mixed type $(8,30.8 \%)$ and epithelioid type $(2$, $7.7 \%)$ in our study.

In the light of the literature, GIST may express SMA (30-40\%), S-100 (5-10\%) and desmin (2$13.4 \%$ ), with changing degrees in relation with prognosis [24]. In our study, the positive expression rates were $26.9 \%$ for SMA, $19.2 \%$ for $\mathrm{S} 100$ and $7.7 \%$ for desmin and our results were similar to the literature. Several studies have shown that desmin and SMA are positively associated with a good prognosis $[8,19,24,25]$. 
Table II. Comparison of demographic and pathologic characteristics of GISTs of the stomach and small intestine

\begin{tabular}{|c|c|c|c|}
\hline \multirow[t]{2}{*}{ Parameter } & \multicolumn{2}{|c|}{ Location of the tumor } & \multirow[t]{2}{*}{$P$-value } \\
\hline & Stomach $(n=23)$ & Small intestine $(n=3)$ & \\
\hline Gender: & & & 0.540 \\
\hline Male & $16(69.6)$ & $3(100.0)$ & \\
\hline Female & $7(30.4)$ & $0(0.0)$ & \\
\hline Age, median (range) & $60.0(35.0-79.0)$ & $66.0(54.0-72.0)$ & 0.469 \\
\hline Operation time, median (range) & $150.0(60.0-500.0)$ & $120.0(100.0-190.0)$ & 0.313 \\
\hline Tumor size, median (range) & $5.0(1.0-13.0)$ & $9.0(5.0-13.0)$ & 0.135 \\
\hline Histologic type: & & & 0.415 \\
\hline Spindle & $15(65.2)$ & $1(33.3)$ & \\
\hline Mixed & $6(26.1)$ & $2(66.7)$ & \\
\hline Epithelioid & $2(8.7)$ & $0(0.0)$ & \\
\hline Ki67, median (range) & $2.0(1.0-20.0)$ & $6.0(5.0-30.0)$ & 0.067 \\
\hline Mitosis rate, median (range) & $3.0(1.0-47.0)$ & $11.0(3.0-30.0)$ & 0.168 \\
\hline Risk: & & & 0.234 \\
\hline Very low risk & $5(21.7)$ & $0(0.0)$ & \\
\hline Low risk & $9(39.1)$ & $0(0.0)$ & \\
\hline Intermediate risk & $3(13.0)$ & $1(33.3)$ & \\
\hline High risk & $6(26.1)$ & $2(66.7)$ & \\
\hline Necrosis & $8(34.8)$ & $1(33.3)$ & 1.000 \\
\hline Hemorrhage & $14(60.9)$ & $3(100.0)$ & 0.529 \\
\hline Metastasis & $3(13.0)$ & $1(33.3)$ & 0.408 \\
\hline Length of hospital stay, median (range) & $7.0(4.0-10.0)$ & $11.0(9.0-15.0)$ & 0.010 \\
\hline Follow-up time, median (range) & $66.0(8.0-120.0)$ & $36.0(8.0-40.0)$ & 0.198 \\
\hline
\end{tabular}

A statistically significant finding was seen in SMA positivity among spindle cells $(p=0.032$ ). In contrast, Hashimi et al. found that most of the spindle cell variety was negative for SMA (83.3\%) and positive for CD34 (73.5\%) [27].

There was no difference in terms of demographic and pathologic features between the gastric and the small intestinal GISTs. Only the length of hospital stay was significantly longer in patients who had small intestinal GISTs $(p=0.010)$. The length of hospital stay was longer because of surgical site infections.

In some Asian studies, the majority of the GISTs generally were low grade tumors [28] and most showed high risk characteristics followed by intermediate and low risk [18, 29, 30]. In this study, the majority of the patients were in the low risk category (34.6\%). Eight (30.8\%) patients were in the high risk, $5(19.2 \%)$ in the very low risk and 4 (15.4\%) in the intermediate risk category.

There are some limitations of this study. First of all, this was a single-center and retrospective study. Secondly, the study had a small sample size. And unfortunately, we could not investigate PDFGRA mutations.

\section{Conclusions}

GISTs are quite rare tumors of the gastrointestinal tract, but accurate diagnosis with immunohistochemical staining is vital for the treatment and management of the disease. Moreover, for prevention of misdiagnosis of GISTs, we need to conduct prospective, randomized, multicenter studies with a large sample of patients. 


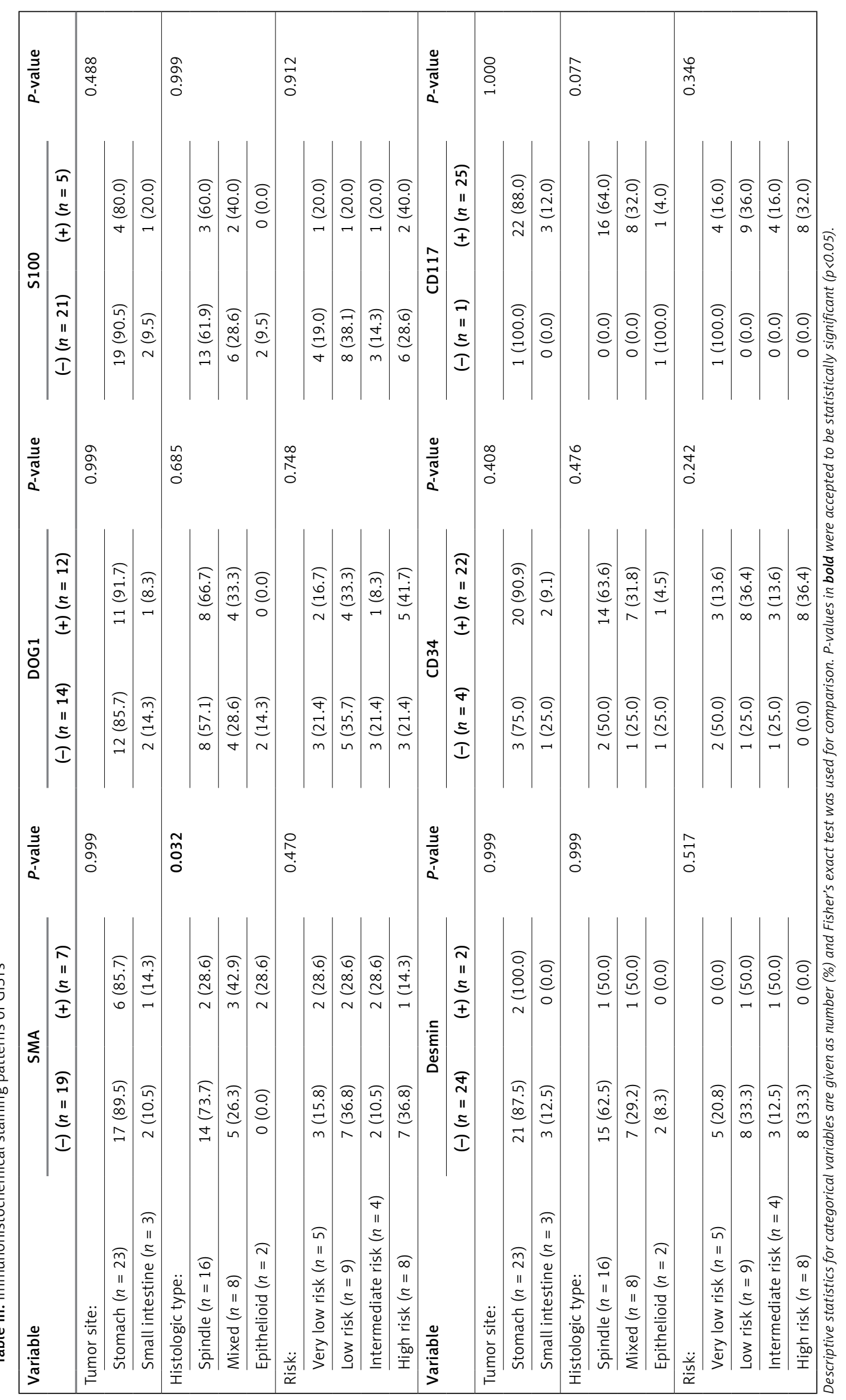




\section{Conflict of interest}

The authors declare no conflict of interest.

\section{References}

1. Duensing A, Heinrich MC, Fletcher CD, Fletcher JA. Biology of gastrointestinal stromal tumors: KIT mutations and beyond. Cancer Invest 2004; 22: 106-16.

2. Kindblom LG, Remotti HE, Aldenborg F, Meis-Kindblom JM. Gastrointestinal pacemaker cell tumor (GIPACT): gastrointestinal stromal tumors show phenotypic characteristics of the interstitial cells of Cajal. Am J Pathol 1998; 152: 1259-69.

3. Schaefer IM, Mariño-Enríquez A, Fletcher AJ. What is new in gastrointestinal stromal tumor? Adv Anat Pathol 2017; 24: 259-67.

4. Hwang SJ, Blair PJ, Britton FC, et al. Expression of anoctamin 1/TMEM16A by interstitial cells of Cajal is fundamental for slow wave activity in gastrointestinal mus cles. J Physiol 2009; 587: 4887-904.

5. Rubin BP, Heinrich MC, Corless CL. Gastrointestinal stromal tumors. Lancet 2007; 369: 1731-41.

6. Miettinen M, Lasota J. Gastrointestinal stomral tumors. Gastroenterol Clin North Am 2013; 42: 399-415.

7. Joensuu H. Risk stratification of patients diagnosed with gastrointestinal stromal tumor. Hum Pathol 2008; 39: 1411-9.

8. Miettinen M, Sobin LH, Lasota J. Gastrointestinal stromal tumors of the stomach: a clinicopathologic, immunohistochemical, and molecular genetic study of 1765 cases with long-term follow-up. Am J Surg Pathol 2005; 29: 52-68.

9. Lai EC, Lau SH, Lau WY. Current management of gastrointestinal stromal tumors - a comprehensive review. Int J Surg 2012; 10: 334-40.

10. Miettinen M, Fletcher CDM, Kindblom LG, Tsui WMS Mesenchymal tumors of the stomach. In: WHO classification of tumors of the digestive system. $4^{\text {th }}$ edn. Bosman FT, Carneiro F, Hruban RH, Theise ND (eds). IARC, Lyon 2010; 74-9.

11. Miettinen M, Makhlouf H, Sobin LH, et al. Gastrointestinal stromal tumors of the jejunum and ileum: a clinicopathologic, immunohistochemical, and molecular genetic study of 906 cases before imatinib with long-term follow-up. Am J Surg Pathol 2006; 30: 477-89.

12. Kern A, Görgens H, Dittert DD, et al. Mutational status of KIT and PDGFRA and expression of PDGFRA are not associated with prognosis after curative resection of primary gastrointestinal stromal tumors (GISTs). J Surg Oncol 2011; 104: 59-65.

13. Tan CB, Zhi W, Shahzad G, Mustacchia P. Gastrointestinal stromal tumors: a review of case reports, diagnosis, treatment, and future directions. ISRN Gastroenterol 2012; 2012: 595968.

14. Kang GH, Srivastava A, Kim YE, et al. DOG1 and PKCare useful in the diagnosis of KIT-negative gastrointestinal stromal tumors. Mod Pathol 2011; 24: 866-75.

15. Sui XL, Wang H, Sun XW. Expression of DOG1, CD117 and PDGFRA in gastrointestinal stromal tumors and correlations with clinicopathology. Asian Pacific J Cancer Prev 2012; 13: 1389-93.

16. Kiśluk J, Zińczuk J, Kemona A, et al. Expression of CD117, DOG-1, and IGF-1R in gastrointestinal stromal tumours - an analysis of 70 cases from 2004 to 2010. Gastroenterology Rev 2016; 11: 115-22.
17. Miettinen M, Majidi M, Lasota J. Pathology and diagnostic criteria of gastrointestinal stromal tumors (GISTs): a review. Eur J Cancer 2002; 38 (Suppl 5): S39-51.

18. Kapoor R, Khosla D, Kumar P, Kumar N, Bera A. Five-year follow up of patients with gastrointestinal stromal tumor: recurrence-free survival by risk group. Asia Pac J Clin Oncol 2013; 9: 40-6.

19. Miettinen M, Lasota J. Gastrointestinal stromal tumors: review on morphology, molecular pathology, prognosis and differential diagnosis. Arch Pathol Lab Med 2006; 130: $1466-78$

20. Goh BK, Chow PK, Yap WM, et al. Which is the optimal risk stratification system for surgically treated localized primary GIST? Comparison of three contemporary prognostic criteria in 171 tumors and a proposal for a modified Armed Forces Institute of Pathology risk criteria. Ann Surg Oncol 2008; 15: 2153-63.

21. Güler B, Özyılmaz F, Tokuç B, Can N, Taştekin E. Histopathological feautures of gastrointestinal stromal tumors and the contribution of DOG1 expression to the diagnosis. Balkan Med J 2015; 32: 388-96.

22. Fujimoto Y, Nakanishi Y, Yoshimura K, Shimoda T. Clinicopathologic study of primary malignant gastrointestinal stromal tumor of the stomach, with special reference to prognostic factors: analysis of results in 140 surgically resected patients. Gastric Cancer 2003; 6: 39-48.

23. Nagasako Y, Misawa K, Kohashi S, et al. Evaluation of malignancy using Ki-67 labeling index for gastric stromal tumor. Gastric Cancer 2003; 6: 168-72.

24. Özgüç H, Yilmazlar T, Yerci Ö, et al. Analysis of prognostic and immunohistochemical factors in gastrointestinal stromal tumors with malignant potential. J Gastrointest Surg 2005; 9: 418-29.

25. Bülbül DG. Gastrointestinal stromal tumors: a multicenter study of 1160 Turkish cases. Turk J Gastroenterol 2012; 23: 203-11.

26. Jumniensuk C, Charoenpitakchai M. Gastrointestinal stromal tumor: clinicopathological characteristics and pathologic prognostic analysis. World J Surg Oncol 2018; 16: 231.

27. Hashimi AA, Faraz M, Nauman Z, et al. Clinicopathologic features and prognostic grouping of gastrointestinal stromal tumors (GISTs) in Pakistani patients: an institutional perspective. BMC Res Notes 2018; 11: 457.

28. Hasegawa T, Matsuno Y, Shimoda T, Hirohashi S. Gastrointestinal stromal tumor: consistent CD117 immunostaining for diagnosis, and prognostic classification based on tumor size and MIB-1 grade. Hum Pathol 2002; 33: 669-76.

29. Rauf F, Bhurgri Y, Pervez S. Gastrointestinal stromal tumors: a demographic, morphologic and immunohistochemical study. Indian J Gastroenterol 2007; 26: 214-6.

30. Kim MK, Lee JK, Park ET, et al. Gastrointestinal stromal tumors: clinical, pathologic features and effectiveness of new diagnostic criteria. Korean J Gastroenterol 2004; 43: 341-8. 